\title{
Development, what does it really mean?
}

\author{
WANNINAYAKA M. SEMASINGHE \\ PROFESSOR
}

Department of Economics, University of Kelaniya, Sri Lanka

e-mail: sema23@kln.ac.1k, semasinghe_wanninayake@yahoo.com

Keywords capabilities, economic growth, entire human society, individual income, modern development ideologies

Abstract "Development" is the most commonly used single word by economists, policymakers, international financial institutions and politicians. Although, as a polysemic word, "development" has different meanings - it is used largely to describe an improvement in the quality of life of people. Initially, development was perceived as the growth of domestic, national or individual income. Over time, the perception of development was broadened, and now it encompasses various dimensions in defining development. In addition to the traditional economic elements, it includes many socioeconomic and political dimensions such as poverty, inequality, unemployment, freedom, democracy, dignity, self-respect and self-esteem. UNDP defines development as a process of enlarging people's choices, while Sen defines it as a process of expansion of freedoms. These choices or freedoms lead to an improvement in the quality of life of people and there is no argument about that. However, as I perceive it, development is not a process as considered in terms of traditional and modern development ideologies, but a superior status that human beings strive to capture or reach. Expansion of choices or freedoms and the elimination of poverty, inequality, etc. are the processes that convey people to the development. The policies and programs drawn up to achieve the improvement of so-called choices or freedoms are the instruments that expand the processes. These processes will end when the entire human society reaches the so-called pinnacle of development.

\section{Introduction}

During their entire lifetime, from birth to death, people are constantly striving to collect and achieve material and non-material benefits to fulfill their desires and needs. However, it is very rare to see someone who is entirely satisfied with this process. Meanwhile, enormous variations in the living standards could be observed among peoples, families, countries, etc. Though very few families enjoy comfortable lives with high income and wealth, big houses, luxury motor vehicles, high quality clothes and other amenities, plenty of food, good health and so on, majority of families in the same country generally live on very little income, poor housing, no vehicles, inadequate food, while wearing rags, and in poor health condition. Whereas many 
families in European countries enjoy comfortable lives, the living conditions of many families in the developing countries of Asia and Africa are intolerable. The people and families who enjoy comfortable lives still strive to earn and collect more material and non-material assets. At the macro level, many developed countries are maintaining most of the important socioeconomic variables such as economic growth, employment, income distribution and living standards at a high level, whereas many developing countries suffer from low economic growth, high level of unemployment, widespread poverty and social inequalities. Moreover, throughout the seven decades following World War II, only a very few countries were able to achieve "developed" country status, with the rest continuing to remain developing countries. Though they are still referred to as "developing" countries, they have achieved a relatively higher level of material progress. This labelling will continue without an end since the desires and aspirations of human beings are unlimited in nature. Further, no one believes that human society will either become a utopian type or a communist type, where all people enjoy equal living standards. Therefore, economists, policymakers, development activists and others will continue to struggle with these problems. This will lead to the development of a logically rich body of literature on the subject of development and the behavior of mankind and national economies.

Within this context, a number of questions generally arise. Some of them are: what are the reasons behind the disparities among families and among countries? How can we understand this situation? Is there a relationship between these disparities and the process of development? In a broader sense, why are some countries affluent while others are poor? Why are some countries categorized as developed and others as developing or underdeveloped or less developed? Is development good for everyone? Among these many questions, this paper endeavors to address a very common problem; i.e. have we understood what "development" is accurately?

\section{What is development?}

Development is an all-encompassing word, which is frequently invoked in every discipline, policy dialogue, as well as day to day happening. In fact, this word is used more frequently in developing countries than in developed countries. There are so many institutions, organizations and departments that have the word "development" as part of their name in developing countries (Dhal, 1997). A good or possibly bad example of this is the Development Lotteries Board that is involved in selling lottery tickets in Sri Lanka.

The term "development" is polysemic, i.e. it has many meanings. It is a term that is capable of giving variety of meanings (Lord Robbins, 1966). Mostly, it refers to positive changes or improvements. Over time, understanding of the term "development" has been broadened to cover numerous concepts. Although at present it is generally used by economists to describe changes in the living standard of human beings, its usage is not limited solely to this economic phenomenon but rather it applies to a multidimensional process that involves changes in the entire social system (UNDP, 1990). In relating to human society, it covers changes in the material indicators such as GDP, GNP, individual income and wealth, local and foreign investments as well as more comprehensive qualitative measures such as poverty, inequality, self-esteem, dignity, happiness, democracy and freedom. As a broad dynamic process, development means different 
things to different people. It defines different individuals, organizations, firms etc. in different ways based on the disciplines, perceptions, associated contexts, experiences, political ideologies, value judgments and so on. Thus, it is impossible to give a general answer to the question "what is development?" (Dhal, 1997). Generally, as the term "development" covers many fields of studies and disciplines that touch upon the behavior of human beings, it has accumulated a vast body of literature around it, over the course of centuries.

As per the Western discourse, development means a qualitative improvement in the wellbeing of people. As P. Routledge (1995) highlighted, the term development conveys a feeling that something has changed and that this change implies betterment, advance, optimism, progress and a general improvement of the human condition. However, these explanations do not do justice to what the term "development" really means. In fact, it is something broader than that! As D. Seers (1969) highlighted, "development is inevitably treated as a normative concept, as almost a synonym for improvement". Then the question arises as to who determines what is improvement and what type of improvements should be regarded as development? In a broader sense, some have understood development as a social change (Apter, 1987; Kulkarni, Ranjan, 1992). The UNDP (1990) clearly emphasized that "people are the real wealth of a nation" and "the objective of development should be to create an enabling environment for people to enjoy long, healthy and creative lives", and also that "development is primarily and fundamentally about people" (UNDP, 2010). These declarations clearly affirm that the changes or improvements that take place through the process of development are associated with human lives. The second question that arises is what type of change is desired? The reason for asking this is because improvements can take place in many fields, for instance in the field of medical treatment as well as in the production of nuclear weapons! However, a third question still remains and that is "What type of improvements?".

Economists have used different working definitions for development at different times depending on the tasks that they faced. In the policy discourse, understanding more precisely the meaning of the term "development" is very important because it helps policymakers to design appropriate policy measures to achieve their goals. As per D. Seers (1969), various problems can arise during the process of development and to overcome them we have to keep on the improving policy. In order to do this, we have to first identify our goals, formulate suitable measures of progress, and judge the relative importance of various problems competing for attention.

\section{Development as Economic Growth}

After World War II, the process of development became a prominent practice in the countries of Asia, Africa, Latin America, the Caribbean and the South Pacific, which had all been categorized as the Third World, the South, less-developed countries, or as developing countries. Leaders and policymakers of these countries kept striving to formulate and implement a range of policies and programs to achieve their development targets. Until the 1970s, development was understood purely in economic terms, when it was assumed that increasing the production capacity of a nation would automatically improve the quality of life of the people through trickle-down effect. 
Development was measured in relation to the income per head and as the ready availability of goods and services as distinct from the experiences or satisfactions felt by the people (Lord Robbins, 1966). The growth of real gross domestic product (GDP) or sometimes gross national product (GNP) was considered as development. Indeed, this line of thinking is not new to economists, because the origin of economics was based on wealth. The classical economists defined economics as a study of the nature of wealth and the factors responsible for the generation of wealth within a nation. Neo-classical economists have said that economics is the study of mankind and the material requisites essential for its well-being.

The growth ideology was favored by the World Bank too. Real GDP or GNP increases only when the volume of output increases. Accordingly, GDP/GNP growth rate as well as GDP per capita were used to measure the progress of development. During this period, quite unintentionally, economic growth became synonymous with development. According to this ideology, it was believed that in the case of a stagnant economy, boosting the growth rate for several years continuously will assure the well-being of the people due to the trickle-down effect (Todaro, 2003, p. 50). However, as ascertained later from the experience gathered, this was one of the big mistakes made by economists and policymakers.

In the hope of enjoying benefits of growth, less developed countries focused mainly on growth oriented economic policies. In this endeavor, rapid industrialization was seen as the motive power required to accelerate growth. When the industrial sector was given priority in the policy arena, it was expected that the service sector that is closely associated with the industrial sector would also become more robust. In fact, this happened in many developing countries but at the cost of the agricultural sector, which constituted the main livelihood of a majority of the rural inhabitants of those countries. Due to these changes it was expected that the importance of the agricultural sector in generating national income would decline gradually, while the share of the industrial and service sectors would increase. As a result, the leading role of the agricultural sector in export earnings and providing employment was usurped by the manufacturing and service sectors. This ideology further supposed that this process would finally bring benefits to the masses in the form of more employment and better education, health, housing etc., which are known as non-economic social aspects of the people. The changes that are brought about in the entire economy and human lives through this process is known as "economic development". Economic growth and economic development tended to reinforce each other. When an economy grows continuously, the structure of the economy will change. When structure of the economy changes, it will lead to an increase in the production capacity of the economy. The reality though is that economic development will not necessarily improve the quality of life of the people.

\section{From raw growth to growth with equity}

This situation that prevailed in many developing countries in the 1970s forced economists, policymakers, decision makers, etc. to rethink the meaning of development, as well as to reorder the development priorities.

By the 1970s, many developing countries were able to realize the growth targets, thereby achieving attractive material progress. In the 1980s and 1990s the national income of some 
developing countries increased significantly. The structure of the economies of those countries changed notably and industrial and service sectors came to the forefront. However, living standards of a large part of the common people of those countries had not improved as expected. Instead, it was common to see increasing unemployment, widespread poverty and increasing inequality in income distribution (Todaro, 2003). The situation further deteriorated due to the slow or negative growth of GDP in the 1980s in many developing countries. Meanwhile, most of the developing countries that had implemented growth-oriented strategies using money taken from countries with surplus capital and from international financial institutions failed to make the repayments due to various reasons, and as a result fell into a "debt crisis" in the 1980s. The World Bank and IMF then had to introduce a comprehensive policy package known as "Structural Adjustment Program - SAP" in the 1980s to help these countries.

In fact, the problems faced by developing countries were the inevitable outcome of their policy orientation. Unfortunately, except for focusing on material growth, the growth ideology of development did not pay necessary attention to important social aspects such as unemployment, inequality and poverty that affected well-being. The appearance of these social ills contradicted the theoretical belief that the benefits of growth will trickle down to the masses. So, in practice, things did not happen as expected. Another very important point was that policymakers, economists, as well as development agencies etc. either purposely or accidentally overlooked the key weakness of relying only on GDP or national income growth. GDP or national income growth figures do not give any indication of the distribution of income or the actual beneficiaries of this growth.

The prevailing situation proved that economic growth alone cannot improve the living standard of the masses. Indeed, it is obvious now that the process of development consists of many aspects other than economic growth. As highlighted by J. Dhal (1997), economic growth is not synonymous with development, but it is only a means to achieve the development goals. This was pointed out by Sir Arthur Lewis even as far back as in 1955 in his book "The Theory of Economic Growth". Nevertheless, economists continued to focus on increasing national income because, according to D. Seers (1969), it provided a convenient basis to quantify, analyze and build models. Further, he highlighted that this resulted in confusing development with economic development and economic development with economic growth.

According to D. Seers (1969), poverty, unemployment and inequality are the three elements that development is expected to eliminate. Fifty years ago he clearly pointed out that:

The questions to ask about a country's development are therefore: What has been happening to poverty? What has been happening to unemployment? What has been happening to inequality? If all three of these have declined from high levels, then beyond doubt this has been a period of development for the country concerned. If one or two of these central problems have been growing worse, especially if all three have, it would be strange to call the result 'development', even if the per capita income has doubled.

This clearly indicates that poverty, unemployment and inequality are the central factors that determine the well-being of the people of a country. Further, he added that unless the planning is done with the aim of reducing poverty, unemployment and inequality, it cannot be considered as 
a development plan. However, this does not mean that in the development process national income or GDP growth is totally worthless. Growth of GDP or national income has a significant role in augmenting the potential for development. As UNDP (1990) highlighted, "people also want higher incomes as one of their options. But income is not the sum total of human life". The situation that existed realistically illustrated that development is not simply limited to the growth of GDP or national income but is a multidimensional process involving changes in the entire social structure. In the 1990s the World Bank gave emphasis to the other dimensions such as better education, higher standard of health and nutrition, less poverty, a cleaner environment, better quality of opportunity, greater individual freedoms, and a richer cultural life (World Bank, 1991). In fact, this was a crucial transformation, because the World Bank is one of the pioneer forces that propagated the ideology of GDP growth for development and provided the theoretical, technical, financial, and consultative assistance to accelerate growth in developing countries.

In order to address the emerging issues such as poverty, inequality and unemployment, it was necessary to implement income redistribution strategies in combination with growth strategies. Inspired by this line of thought and assisted by international organizations, the economists and development activists, etc. in many developing countries began implementing income redistribution measures in the form of various programs focusing on poverty alleviation, health service, education, housing, and different types of relief activities since the 1980s. Growth with equity has become the new face of development presently. Implementation of social "safety nets" in these countries is being supported by the World Bank too.

\section{Development as a process of enlarging human choice and capabilities}

The UNDP (1990) perceived development as a process of expanding human choices. This process has been defined as "Human Development". It is a state or condition that involves more than maintaining a high GDP growth rate or high national income and so it also strives to reduce poverty and inequality etc. at the macro level by promoting the achievement of material possessions such as income, wealth, commodities, and capital accumulation at the micro level, while at the same time expanding the people's ability to make choices. According to the UNDP, development is nothing other than improving the quality of life of people. Quality of life for them would be improved by expanding their choices. The choices are the essential qualities that people need to have a better life. The UNDP has outlined the three most important choices, which are, a) to lead a long and healthy life, b) to acquire knowledge, and c) to have access to resources needed for a decent standard of living. In addition to these choices, a range of other choices have also been mentioned. Those include broader parameters such as political freedom, guaranteed human rights and self-respect. As mentioned in the Report in 1990, human development has two sides. One is the formation of a person's capabilities, which is "a set of vectors of functionings, reflecting the person's freedom to lead one type of life or another" as A.K. Sen (1992, p. 40; 2000, p. 75) defined. For example, such qualities as improved health, knowledge and skills. Expansion of the capabilities of individuals and make use of same in various ways, improves the quality of life of people. 
There is a close parallel between the views of UNDP and of Amartya Sen on development. A.K. Sen $(2000$, p. 3) argued that development is a process of expanding the real freedoms that people enjoy. Freedoms imply the capability to actively function in a society. According to the UNDP approach, expansion of choices builds the capabilities that are needed for better life, but that may not by themselves improve the quality of life, if those capabilities are not really functioning. According to Sen, functionings are the states and activities constitutive of a person's being while capabilities are the alternative combinations of functionings that are feasible for a person to achieve. Functionings are, in a sense, more directly related to living condition, since they are different aspects of living conditions. Capabilities, in contrast, are notions of freedom, in the positive sense of "what real opportunities you have regarding the life you may lead" (Sen, 1987, p. 36). This implies that choices themselves may not expand the quality of life of people. Hence, to achieve a better life, not only expansion of choices but expansion of realized choices, or in other words, realized freedoms are important. As Sen admits, growth of GDP or national or personal incomes are important to enable expansion of freedoms enjoyed by the people in a society. In order to attain the development goals, A.K. Sen (2000) mentioned that constraints such as poverty, tyranny, poor economic opportunities, systematic social deprivation, neglect of public facilities, as well as intolerance or over activity of the respective states should be removed.

\section{Development as a superior status}

All the ideologies on development are centered on the accomplishments of material and nonmaterial social elements. As commonly accepted GDP or national income growth plays an important role as a means to development. Sen's ideology on development as the expansion of freedoms has broadened the scope of development. Since the desires of human beings are never satiated, the elements of development or freedoms, as defined by Sen, will keep on increasing. Based on this nature, development is judged as a process. However, if development is a state that the human being can reach (whenever!), there should be an end. Then, where is the end of this process? If we can create (anyhow!) a complete list, which includes all possible freedoms or choices a society could achieve, as Sen defined the list of functionings, and when the society has accomplished all these freedoms or choices at the optimum level, then can it be concluded that the society is developed? Just expansion of the ability to achieve choices or freedoms or eliminating poverty and inequality or reducing unemployment may not bring development to the people. Instead, all people in the society should realize or achieve these choices or freedoms. In this sense, one of the important questions that arise is: have all peoples in the so-called developed countries of the West or Europe achieved those choices fully? If not, how can these countries be labeled as developed? Undoubtedly, majority of the people in these countries have achieved relatively higher levels of material progress. But, in absolute terms, living standards of a significant part of the people in these countries are still relatively well below the norm. Meanwhile, these countries are constantly struggling to progress further, employing various strategies. This indicates that these countries have still not reached the state of true development. 
What all these imply is that development is not a process as both traditional and modern intellectual views maintain but rather a status, which exhibits a superior level of quality of life! The choices according to the UNDP or the freedoms as Sen termed are the "processes" that people or societies utilize as the means to achieve this superior status.

The set of policies and programs on socioeconomic progress followed by a society leads to the processes of achieving freedoms or choices. Hence, these policies and programs are the means to achieve development. The achieved functionings or the choices or freedoms convey the society to the state of development. The association between means or instruments, process and development clearly portraits Figure 1 below.

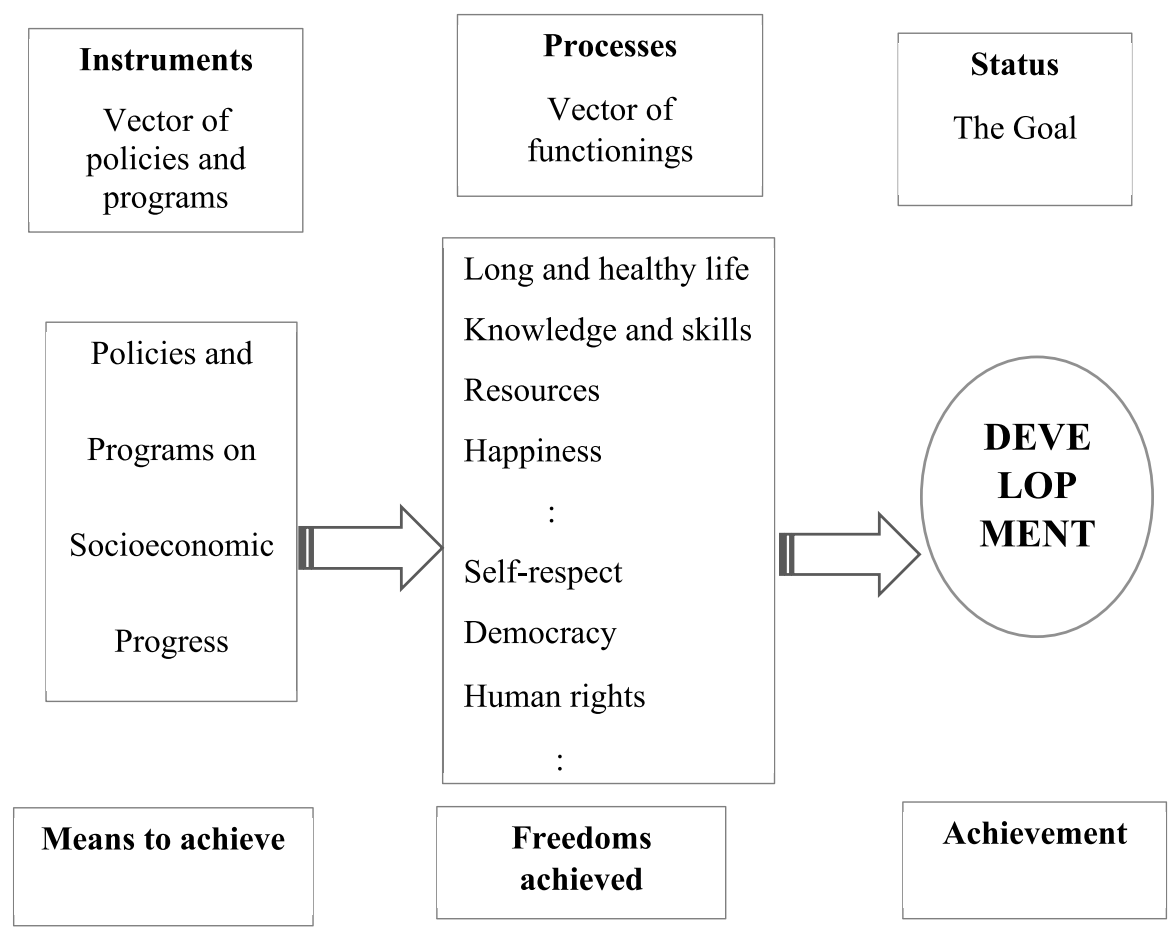

Figure 1. Association between instrument, process and development

Due to their mutual interdependence and interactions among individuals, families, societies, and countries in the process of improving their well-being, one cannot attain the status of "true development" alone. These single units can reach only up to the intermediate level of development.

\section{Conclusion}

The perceptions of development have broadened over time encompassing many aspects. Some of them can be empirically evaluated, such as income, wealth, consumption, shelter etc., while some others that cannot be quantified and measured such as self-esteem, dignity, happiness, 
etc. Undoubtedly, the list will expand in the future, adding more and more aspects. Among the various accepted wisdoms, Sen's idea on the process of development is close to the reality though it is complex and hard to reach. However, all these explanations on development consider development as a process. As I perceive it, development is not a process but a superior status like "beatitude" (nibbana) in Buddhism, or "heaven" in Catholicism, which human beings strive to capture or reach. Indeed, that is true development. No one knows its exact shape or dimensions or colour etc. because it has a dynamic status. No one can set boundaries or limits to this superior status. When we reach up to a certain level of living, the goal will recede further just as with the horizon; although we can see what appears to be the end, when we try to come near it, the end moves further away encompassing new facets. All attempts that people make to reach this position are "processes". Expanding the freedoms or choices are the processes used to reach "development". These processes will end when the entire society reaches the state of "true development".

\section{References}

Apter, D.D. (1987). Rethinking Development: Modernization, Dependency and Postmodern politics. London: SAGE Publications.

Chambers, R. (1997). Whose Reality Counts? Putting the first last. London: Intermediate Technology Publication.

Seers, D. (1969). The meaning of Development. Institute of Development. IDS Communication Series No. 44.

Dhal, J. (1997). Cry for Water: Perceptions of Development in Bniga District in Zimbabwe. Sweden: School of Economics and Commercial Law, University of Gothenburg.

Kulkarni, G.S., Ranjan, R.S. (1992). Perceptions of development as empowerment In: M.O. Cinnéide, S. Grimes (eds), Planning Development of Marginal Areas (pp. 135-142). Center for Development Studies, Social Science Research Center: University Collage of Galway.

Lord Robbins (1966). The theory of Economic Development in the History of Economic Thought. Macmillan: St Martin's Press.

Routledge, P. (1995). Resisting and reshaping the modern: social movements and the development process. In: P. J. Taylor, M.J. Watts, R. J. Jhonstan (eds), Geographies of Global Change: Remapping the World in the Late Twentieth Century (pp. 263-279). Blackwell. Oxford.

Semasinghe, W.M. (2016). Growth, Pro-poor Growth, Inclusive Growth and Poverty. SAMPRASADANA, Department of History: University of Kelaniya.

Sen, A.K. (1987). The Standard of Living, Cambridge: Cambridge University Press.

Sen, A.K. (1992). Inequality reexamined. Oxford University Press.

Sen, A.K. (2000). Development as a Freedom. Oxford University Press.

Todaro, M.P. (2003). Economic Development. England: Addison Wesley Longman Limited.

UNDP (1990). Human Development Report - 1990. New York: Oxford University Press/ Oxford.

UNDP (2010). Human Development Report 2010: The Real Wealth of Nations - Pathways to Human Development. New York. Retrieved from: http://hdr.undp.org/en/content/human-development-report-2010.

World Bank (1991). World Development Report, New York: Oxford University Press. 